\title{
Are Inflation Expectations Rising from the Ashes?
}

\author{
Jeremy M. Piger
}

$\mathrm{T}$ he University of Michigan's Survey of Consumers reported a drastic decline in consumer confidence following the devastating effects of Hurricane Katrina.

This crumbling confidence was widely reported, and its significance as an indicator of economic weakness debated. Less well publicized was the large increase in expectations of future inflation that was also recorded in this survey. For example, at the end of August, just before Hurricane Katrina, respondents in the Michigan survey were expecting the inflation rate over the subsequent 12 months to be 3.1 percent. However, by the end of September, the same measure of inflation expectations was 4.3 percent. As the black line in the accompanying chart shows, this increase in inflation expectations is large by historical precedent and brings one-year-ahead inflation expectations to a level not seen since 1990 .

Inflation expectations give a reading of how credible the public believes monetary policymakers are in their commitment to fight inflation; as a result these expectations are an important gauge used in the practice of monetary policy. That is, if the public believes monetary policymakers are credible in their stated goal of keeping inflation low and stable, then inflation expectations will stay low and stable. One reason credibility is important is that containing inflation expectations can be a first step in containing inflation itself. This is because expectations of higher future inflation might be negotiated into various sorts of pricing contracts, such as labor contracts, thereby creating the expected inflation.

To interpret the rise in inflation expectations from the Michigan survey, a natural first question is, to what extent is this measure a reliable predictor of future inflation? After all, this survey is conducted by polling consumers who have no special expertise or sophistication in forecasting inflation, raising a legitimate question of how seriously one should take the results. However, economists N. Gregory Mankiw, Ricardo Reis, and Justin Wolfers have shown that, when evaluated over the past 20 years, the median survey response from the Michigan survey was at least as accurate of a forecast of future inflation as those produced by professional forecasters. ${ }^{1}$

Given this, should monetary policymakers at the Federal Reserve be concerned that inflation expectations are getting out of control, suggesting they have been too slow to tighten policy in recent years? To evaluate this question, it is useful to look not just at expectations of inflation over the next year, but also over longer horizons. As the green line in the figure shows, expectations of inflation from the Michigan survey over the horizon of the next 5 to 10 years have increased only slightly in recent months and are not at abnormally high levels relative to those seen in the past several years. This divergence between shorter and longer horizon inflation expectations suggests that the rise in inflation expected over the next year is being driven by temporary factors, such as increases in energy prices, and not by a loss of confidence in the ability or resolve of Federal Reserve policymakers to control inflation more broadly. This is good news for the Federal Reserve, as it suggests the public is convinced policymakers are taking, and will continue to take, appropriate actions to keep inflation low over longer horizons.

${ }^{1}$ N.G. Mankiw, R. Reis, and J. Wolfers, "Disagreement about Inflation Expectations," NBER Macroeconomics Annual 2003.

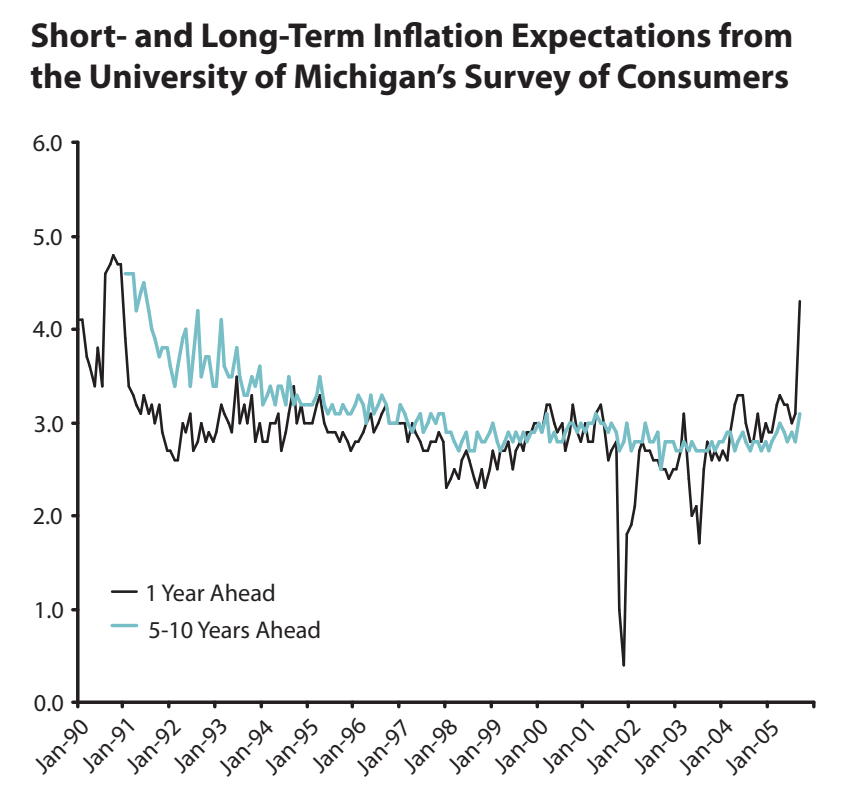

